\title{
Evaluation of The Antifungal Activity of Nasturtium officinale (watercress) Oil with Calcium Hydroxide against Candida Albicans Isolated from Root Canal
}

\author{
Mustafa W. Abdul Kareem ${ }^{(1)}$, Zainab A. Al Dhaher ${ }^{(2)}$ \\ https://doi.org/10.26477/ibcd.v33i4.3012
}

\begin{abstract}
Background: The interest in herbal extracts as antimicrobial agents has increased over the past few years in endodontic therapy. Nasturtium officinale (watercress) is a promising plant with great medicinal values. This study aimed to investigate the antifungal activity of watercress oil in combination with calcium hydroxide against Candida albicans as intracanal medicament.

Materials and Methods: Candida albicans was isolated from patients with necrotic root canal or failed root canal treatment. The sensitivity of Candida albicans to different concentrations of watercress oil extract was determined by using the agar well diffusion method in comparison with calcium hydroxide paste. The agar plate method was used to determine the minimum fungicidal concentration (MFC) of the tested oil against the fungus. The combination of the oil extract of Nasturtium officinale with calcium hydroxide was evaluated and compared to calcium hydroxide paste with iodoform by using the agar well diffusion method.

Results: The oil extract exhibited antifungal activity against Candida albicans, this activity was found to be increased as the concentration of extract increased. The tested combination of watercress oil extract with calcium hydroxide revealed larger inhibition zones than the ones formed by each tested agent individually.

Conclusion: The oil extract of Nasturtium officinale is active against Candida albicans suggesting its potential to be used as an intracanal medicament alone or in combination with calcium hydroxide.

Keywords: Nasturtium officinale, Oil extract, Candida albicans, Intracanal medicaments. (Received: 22/7/2021, Accepted:
\end{abstract} 29/8/2021)

\section{INTRODUCTION}

Successful root canal treatment is accomplished by complete disinfection of root canals and removal of debris by efficient delivery of antimicrobial agents. (1) The persistence of microorganisms and their resistance to the disinfection measures are the major cause of root canal treatment failure. (2) Enterococcus faecalis is the most commonly associated bacterial species with periapical infection and failure of root canal treatment. ${ }^{(3)}$ Candida albicans is the most isolated fungus from root canal system which plays a major role in root canal treatment failure. ${ }^{(4)}$ All this can occur as a result of inefficient shaping of the canals, absence of apical sealing, voids in the restoration of the clinical crown, missed canals. ${ }^{(5)}$

(1) MA Student, Al Hadi University College, Dentistry Department. Baghdad, Iraq

(2). Professor, Department of Basic Sciences, College of Dentistry, University of Baghdad.

Corresponding author: mustafa code108@yahoo.com
Intracanal medications with anti- microbial action are used with the intention of maximizing the disinfection of root canals. ${ }^{(6)}$ Calcium hydroxide is the most commonly used intracanal medicament ;researchers investigated its combination with a plethora of vehicles in order to enhance its antimicrobial properties significantly. ${ }^{(7)}$ Candida albicans has been repeatedly recovered from the canals of retreatment cases especially the ones with persistent infections. ${ }^{(8)}$ It possesses several virulence factors such as adherence to many surfaces including dentin and root filling materials, produces hydrolytic enzymes, undergoes morphologic transition, form biofilms, evades and modulates the host defense. ${ }^{(9)} \mathrm{A}$ growing resistance of endodontic pathogens to the common antimicrobials has been noticed and led to an increasing efforts to the production of high-value phytochemicals that could be used as irrigants and intracanal medicaments. Nasturtium officinale (watercress) plant is currently received a lot of attention and many studies reported its beneficial properties and confirmed it therapeutic 
potential for the treatment of many oral diseases. ${ }^{(10)}$

\section{MATERIALS AND METHODS \\ Oil extract preparation}

Nasturtium officinale (watercress) was purchased from the local market in Baghdad city, Iraq. After cleaning and washing, only the leaves were collected, air dried, grinded and stored in airtight containers and sent to extraction. The extraction was prepared according to the method described in the study of Mahdavi et al. ${ }^{(11)}$

\section{Patient selection and sample collection}

This study was ethically approved by the Research Ethics Committee at College of Dentistry/ University of Baghdad . It included 30 patients aged (25-45 years) with necrotic or failed treated teeth. The sample was collected after complete isolation of the selected teeth with rubber dam, removal of carious lesions, access opening to the canals and initial instrumentation by ISO type k-files and AF rotary file \#20/04 (Fanta/ China) without any irrigants were made. Sterile saline solution was further applied and agitated with the last file to form a microbial suspension. ${ }^{(12)}$

\section{Isolation of Candida albicans}

Paper points were sterilized by autoclave and then introduced into the canal and kept for one minute until the canal was dry. Thereafter, these paper points were transferred into a tube containing sterile transport media (AMIES) and sent to the laboratory for isolation and identification. ${ }^{(13,14)}$ After been vortexed, the collected samples were streaked on sabouraud dextrose agar (SDA) media and incubated aerobically at $37^{\circ} \mathrm{C}$ for 48 hours.

\section{Identification of Candida albicans}

C. albicans identification was based on microscopical examination (Gram stain), colony morphology (on sabouraud dextrose agar) and germ tube formation test.

\section{In vitro experiments}

Antifungal activity of different concentrations of Nasturtium officinale oil extract against $C$. albicans:

Agar well diffusion method was employed to assess the antifungal activity of the extract. The tested oil was prepared in four concentrations of 5, 10, 15 and $20 \mathrm{mg} / \mathrm{ml}$ in 10\% dimethyl sulfoxide (DMSO). Six wells were prepared in Mueller Hinton Agar (MHA) plates, four of them filled with $100 \mu$ l of the different concentrations of the oil extract and the others with calcium hydroxide paste and DMSO as positive and negative controls respectively. The plates were incubated aerobically for $24 \mathrm{hrs}$., at $37^{\circ} \mathrm{C}$.

\section{Determination of Minimum Fungicidal Concentration (MFC) of the tested oil on $C$. albicans:}

Final concentrations of $10,5,2.5,1.25,0.625$ were prepared from Nasturtium officinale oil and incorporated into a sterile BHI.A to get $10 \mathrm{ml}$ of agar and the tested oil. The experimental bottles were poured into sterile petridishes for a period until they became hard then inoculated by streaking loop full from activated bacteria. The petridishes were incubated for $24 \mathrm{hrs}$. at $37^{\circ} \mathrm{C}$ including the control plate (negative control) which contained BHI.A with microbial inoculum without the addition of the tested oil, and (positive control) plate which contained BHI.A with different concentration of the tested oil without bacterial inoculum. The MFC was determined as the lowest concentration of the oil that killed the fungus. ${ }^{(15)}$

Test the combination effect of Nasturtium officinale oil with calcium hydroxide on $C$. albicans in comparison to calcium hydroxide paste with iodoform:

Agar well diffusion method was employed to assess the antifungal activity of the combination of oil extract with calcium hydroxide paste. The experiment involved mixing equal volume $1: 1$ of the tested oil with calcium hydroxide paste. MFC of oil extract and calcium hydroxide paste with iodoform (readymade) were included in the wells.

\section{Statistical analysis}

Data were analyzed using SPSS (statistical package of social science) software version 25. A one-way ANOVA test was used to compare the inhibition zone among different concentrations of the tested oil. Tukey's HSD test was used to test any statistically significant difference between each two concentrations of the tested extract.

Independent sample t-test was used to compare the inhibition zone between the study and control group.

\section{RESULTS}

\section{Identification of $C$. albicans:}

C. albicans appeared as small oval gram-positive or budding yeast cells under microscope. On SDA, it 
was developed as creamy, white, smooth, pasty convex with yeast smell odor and finally it showed a positive result of germ tube formation.

\section{Antifungal activity of different concentrations of} Nasturtium officinale oil extract against $C$. albicans:

C. albicans was sensitive to all concentrations of Nasturtium officinale oil extract and growth inhibition zones were formed. The diameter of the growth inhibition zone found to increase as the concentrations of the oil increased. In contrary to DMSO, calcium hydroxide paste revealed antifungal activity against $C$. albicans. Analysis of variance (ANOVA) test was used and the results showed that there was a highly significant difference $(\mathrm{P} \leq 0.01)$ among the studied concentrations of oil extract and calcium hydroxide paste (Table 1 and Figure 1).

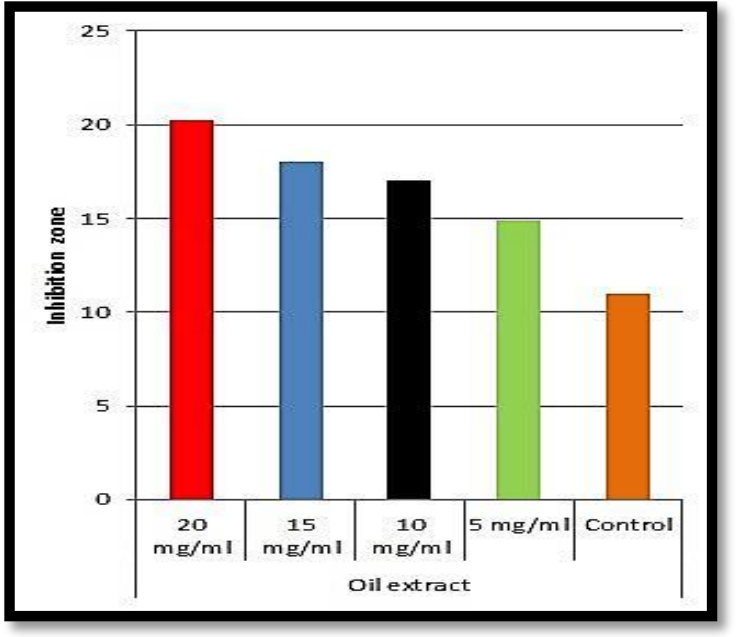

Figure 1: Antifungal activity of Nasturtium officinale oil and calcium hydroxide paste (control) against Candida albicans.

Table 1: Comparison among the antifungal activity (inhibition zone diameter in $\mathbf{m m}$ ) of Nasturtium officinale oil and calcium hydroxide paste (control) against Candida albicans.

\begin{tabular}{llllllll}
\hline \multicolumn{1}{c}{ Oil Conc. } & Mean & S.D. & Min. & Max. & F-test & p-valu \\
\hline $20 \mathrm{mg} / \mathrm{ml}$ & 20.2 & 2.440 & 17 & 25 & & \\
$15 \mathrm{mg} / \mathrm{ml}$ & 18 & 1.826 & 16 & 21 & 32.453 & $0.000^{*}$ \\
$10 \mathrm{mg} / \mathrm{ml}$ & 17 & 2.160 & 14 & 20 & & \\
$5 \mathrm{mg} / \mathrm{ml}$ & 14.9 & 2.025 & 12 & 18 & & \\
Control & 11 & 0.816 & 10 & 12 & & \\
\hline
\end{tabular}

[*] Highly significant

Since the difference was highly significant among extract concentrations and the control, a statistical comparison had been done by using Tukey's HSD test between each two concentrations of Nasturtium officinale oil extract .The results demonstrated that there was a highly significant difference $(\mathrm{P} \leq 0.01)$ among oil extract concentrations except between 20 $\mathrm{mg} / \mathrm{ml}$ and $15 \mathrm{mg} / \mathrm{ml}, 15 \mathrm{mg} / \mathrm{ml}$ and $10 \mathrm{mg} / \mathrm{ml}, 10$ $\mathrm{mg} / \mathrm{ml}$ and $5 \mathrm{mg} / \mathrm{ml}$ the difference was nonsignificant $(\mathrm{P}>0.05)$ (Table 2).

Table 2: Comparison among the antifungal activity (inhibition zone diameter in $\mathbf{~ m m}$ ) between each two concentration of Nasturtium officinale oil and calcium hydroxide paste (control) against Candida albicans.

\begin{tabular}{cclc}
\hline $\begin{array}{c}\text { Oil } \\
\text { Conc. }\end{array}$ & $\begin{array}{c}\text { Compared } \\
\text { with }\end{array}$ & $\begin{array}{c}\text { Mean } \\
\text { difference }\end{array}$ & $\begin{array}{c}\text { P- } \\
\text { value }\end{array}$ \\
\hline $20 \mathrm{mg} / \mathrm{ml}$ & $15 \mathrm{mg} / \mathrm{ml}$ & 2.2 & $0.099^{* *}$ \\
& $10 \mathrm{mg} / \mathrm{ml}$ & 3.2 & $0.005^{*}$ \\
& $5 \mathrm{mg} / \mathrm{ml}$ & 5.3 & $0.000^{*}$ \\
& Control & 9.2 & $0.000^{*}$ \\
& & & \\
$15 \mathrm{mg} / \mathrm{ml}$ & $10 \mathrm{mg} / \mathrm{ml}$ & 1 & $0.776^{* *}$ \\
& $5 \mathrm{mg} / \mathrm{ml}$ & 3.1 & $0.007^{*}$ \\
& Control & 7 & $0.000^{*}$ \\
& & & $0.127^{* *}$ \\
$10 \mathrm{mg} / \mathrm{ml}$ & $5 \mathrm{mg} / \mathrm{ml}$ & 2.1 & $0.000^{*}$ \\
& Control & 6 & $0.000^{*}$ \\
\hline $5 \mathrm{mg} / \mathrm{ml}$ & Control & 3.9 & \\
\hline
\end{tabular}

[*] Highly significant

[**] Non significant

\section{Determination of Minimum Fungicidal Concentration (MFC) of the tested oil on $C$. albicans:}

The minimum fungicidal concentration of oil extract was $2.5 \mathrm{mg} / \mathrm{ml}$.

The combination effect of Nasturtium officinale oil with calcium hydroxide on $C$. albicans in comparison to calcium hydroxide paste with iodoform:

C. albicans was sensitive to the combination of minimum fungicidal concentration of the tested oil and calcium hydroxide paste and growth inhibition zones were formed. Independent sample t-test was used to compare the inhibition zone between the studied combination and calcium hydroxide paste with iodoform as a control. The results revealed that there was a highly significant difference $(\mathrm{P} \leq 0.01)$ between the study and the control group (Table 3 ). 
Table 3: Comparison between the antifungal activity of the study and control groups against Candida albicans.

\begin{tabular}{|c|c|c|c|c|c|c|}
\hline \multirow{2}{*}{$\begin{array}{c}\text { Inhibition } \\
\text { zones } \\
\text { against } C . \\
\text { albicans } \\
\end{array}$} & \multirow{2}{*}{\multicolumn{2}{|c|}{$\begin{array}{r}\text { Study } \\
\text { group }\end{array}$}} & \multicolumn{2}{|c|}{$\begin{array}{l}\text { Control } \\
\text { group }\end{array}$} & \multirow[t]{2}{*}{ t-test } & \multirow[t]{2}{*}{ P-value } \\
\hline & & & Mean & S.D. & & \\
\hline $\begin{array}{c}\text { Combination } \\
\text { of oil extract } \\
\text { with calcium } \\
\text { hydroxide }\end{array}$ & 15 & 2.108 & 8.1 & 0.738 & 9.769 & $0.000^{*}$ \\
\hline
\end{tabular}

\section{[*] Highly significant}

Another statistical comparison was done by using independent sample t-test to study the effect of the studied combination and compare the inhibition zone of the tested oil at MFC value with and without calcium hydroxide. The tested oil with calcium hydroxide revealed antifungal activity against $C$. albicans higher than that of the tested oil alone (larger inhibition zones diameters formation) and the statistical difference was highly significant $(\mathrm{P} \leq 0.01)$ (Table 4).

Table 4: Comparison between the antifungal activity of oil extract with and without calcium hydroxide against $C$ andida albicans.

\begin{tabular}{|c|c|c|c|c|c|}
\hline \multirow{2}{*}{$\begin{array}{c}\text { Inhibition } \\
\text { zones } \\
\text { against } C \text {. } \\
\text { albicans }\end{array}$} & \multirow{2}{*}{$\begin{array}{c}\begin{array}{c}\text { without } \\
\text { calcium } \\
\text { hydroxide }\end{array} \\
\text { Mean S.D. }\end{array}$} & \multicolumn{2}{|c|}{$\begin{array}{c}\text { with } \\
\text { calcium } \\
\text { hydroxide }\end{array}$} & \multirow[t]{2}{*}{$\begin{array}{c}\text { t- } \\
\text { test }\end{array}$} & \multirow[t]{2}{*}{$\underset{\text { value }}{\text { P- }}$} \\
\hline & & Mean & S.D. & & \\
\hline Oil extract & 120.816 & 15 & 2.108 & -4.196 & $0.001 *$ \\
\hline
\end{tabular}

[*] Highly significant

\section{DISCUSSION}

Many studies in the literature reported the application of herbal extracts in endodontics. They have been used as disinfectants of root canals, intracanal medications, sealers for obturating canals and as solvents of gutta percha of previously treated teeth. ${ }^{(16)}$ Plants oil has been reported to have significant fungicidal effects related to its inherent constituents. (17) The results of this study revealed the antifungal activity of Nasturtium officinale oil extract against $C$. albicans and this activity increased as the concentration increased. This finding is supported bya previous study that declared the direct relation of antimicrobial activities to the extract concentration. ${ }^{(18)}$ It could be explained that the higher concentrations of the extract have higher contents of dissolved active constituents. ${ }^{(19)}$ The presence of antimicrobial properties of watercress has been investigated and related to its inherent phytochemicals such as flavonoids and tannins. Flavonoids are naturally occurring antimicrobials capable of inhibition of nucleic acid synthesis, cytoplasmic membrane function and energy metabolism. ${ }^{(20)}$ Tannins are able to inhibit microbial extracellular enzymes, deprive the substrates necessary for microbial growth and interrupt the active transport and electron flow. ${ }^{(21)}$ Several studies reported the antimicrobial activity of Nasturtium officinale extracts against different pathogens. $(22,23,24)$ The combination of oil extract with calcium hydroxide paste showed a positive reaction by demonstrating a larger inhibition zones of $C$. albicans than the inhibition zones formed by each individual agent with a highly significant difference $(\mathrm{P} \leq 0.01)$. This finding suggests that a synergistic or additive effect could be achieved if a higher concentration of oil extract combined with calcium hydroxide paste. Further ex-vivo studies are required to test the diffusion ability of the oil into dentinal tubules.

\section{CONCLUSION}

Watercress oil extract exhibited a worth noticed antifungal activity and it could be an effective herbal alternative to the available synthetic antimicrobials used in root canal treatment.

\section{Conflicts of interest}

The authors have nothing to disclose.

\section{REFERENCES}

1. Urban, K., Donnermeyer, D., Schäfer, E., et al. Canal cleanliness using different irrigation activation systems: a SEM evaluation. Clin. Oral Investig. 2017; 21(9), 2681-2687.

2. Prada, I., Micó-Muñoz, P., Giner-Lluesma, T., et $a l$, A. Influence of microbiology on endodontic failure. Literature review. Med Oral Patol Oral Cir Bucal. 2019; 24(3), e364.

3. Colaco, A.S. Extreme resistance of Enterococcus faecalis and its role in endodontic treatment failure, Prog Med Sci. 2018;2,1.

4. Ashraf, H., Samiee, M., Eslami, G., et al. Presence of Candida albicans in root canal system of teeth requiring endodontic retreatment with and without periapical lesions. Iran. Endod. J. 2007;2(1), 24.

5. Tabassum, S, Khan, FR. Failure of endodontic treatment: The usual suspects. Eur J Dent. 2016;10:144-7. 
6. Murray, PE., Farber, RM., Namerow, KN., et al. Evaluation of Morinda citrifolia as an endodontic irrigant. J. Endod.. 2008; 34(1), 66-70.

7. Athanassiadis, B., Abbott, PV., Walsh, LJ. The use of calcium hydroxide, antibiotics and biocides as antimicrobial medicaments in endodontics. Aust. Dent. J. 2007; 52, S64-S82.

8. Gopikrishna, AV., Kandaswamy, D.J eyavel, RK. Comparative evaluation of the antimicrobial efficacy of five endodontic root canal sealers against Enterococcusfaecalis and Candida albicans. J Conserv Dent. 2006;9:2-12.

9. Persoon, IF., Buijs, MJ., Özok, AR., et al. The mycobiome of root canal infections is correlated to the bacteriome. Clin. Oral Investig. 2017; 21(5), 1871-1881.

10. Chaudhary, S., Hisham, H., Doha, M. A review on phytochemical and pharmacological potential of watercress plant. Asian J. Pharm. Clin. Res. 2018; 11.12: 102-107.

11. Mahdavi, S., Kheyrollahi, M., Sheikhloei, H., et al. Antibacterial and Antioxidant Activities of Essential Oil on Food Borne Bacteria. Open Microbiol. J. 2019; 13(1).

12. Fouad AF. Endodontic Microbiology 1st edition: culture based analysis of endodontic infection by Gunnar dohlen, P 40-65. Wiley; 2009.

13. Al-Hyali, NA. Inhibition of bacterial growth around gutta percha cones by different antimicrobial solutions using antibiotic sensitivity test (An in vitro study). JBCD. 2013; 25(4), 26-32.

14. Skucaite, N., Peciuliene, V., Vitkauskiene, A., et al. Susceptibility of endodontic pathogens to antibiotics in patients with symptomatic apical periodontitis. J. Endod. 2010; 36(10), 1611-1616.
15. Al-Mizrakchi, A. Adherence of mutans Streptococci on teeth surfaces: microbiological and biochemical studies. Diss. PhD Thesis, 1998.

16. Arora, S., Saquib, SA., Algarni, YA., et al. Synergistic effect of plant extracts on endodontic pathogens isolated from teeth with root canal treatment failure: An In Vitro Study. Antibiotics. 2021; 10(5), 552.

17. Chouhan, S., Sharma, K., Guleria, S. Antimicrobial activity of some essential oils-present status and future perspectives. Medicines. 2017;4(3), 58.

18. Bhalodia, NR., Shukla, VJ. Antibacterial and antifungal activities from leaf extracts of Cassia fistula 1.: An ethnomedicinal plant. J. Adv. Pharm. Technol. Res. 2011; 2(2), 104.

19. Weli, TA., Mohammed, A. Effect of ginger extract on Mutans streptococci and candida albicans in comparison to chlorhexidine gluconate. J. Baghdad Coll. Dent. 2013; 25(2), 179-184.

20. Cushnie, TT., Lamb, AJ. Antimicrobial activity of flavonoids. Int. J. Antimicrob. Agents. 2005; 26(5), 343-356.

21. Scalbert, A. Antimicrobial properties of tannins. Phytochemistry.1991; 30(12), 3875-3883.

22. Nikan, J., Khavari, H. In vitro anti-fungal activity of watercress (Nasturtium officinale) extract against Fusarium solani, the causal agent of potato dry rot. J. Herb Drugs. 2014;5(1): 19-24,

23. Sadeghi, B. Synthesis of silver nanoparticles using leaves aqueous extract of Nasturtium Officinale (NO) and its antibacterial activity. Int. J. Med. Microbiol. 2014; 4(2), 428-434.

24. Khan, H., Jan, SA., Javed, M., et al. Nutritional composition, antioxidant and antimicrobial activities of selected wild edible plants. J. food biochem. 2016; 40(1), 61-70.

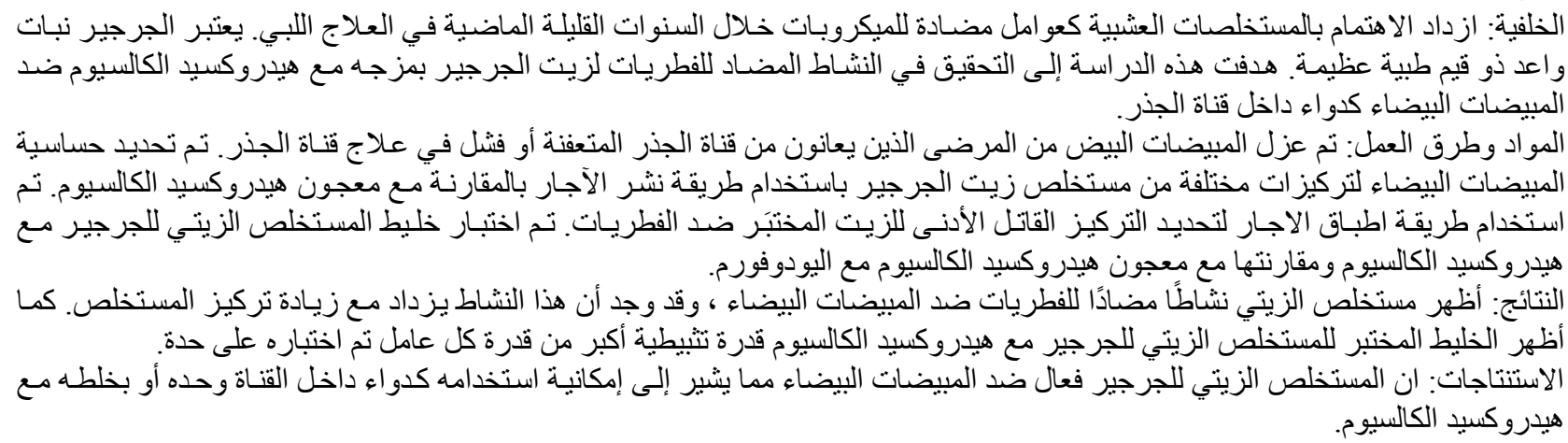

Articles Published by Journal of Baghdad College of Dentistry is licensed under a Creative Commons Attribution 4.0 International License. 